\title{
Perancangan Sistem Pendukung Keputusan Pemilihan Supplier di PT. Alfindo Dengan Metode Analytical Hierarchy Process (AHP).
}

\author{
Ninik Wulandari ${ }^{1}$

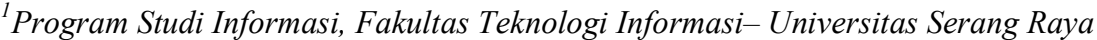 \\ Jl. Raya Cilegon - Serang Km.5 Taman Drangong Kota serang - Banten, indonesia \\ ${ }^{1}$ nieqwulandarieyahoo.co.id
}

\begin{abstract}
PT. Alfindo merupakan perusahaan yang bergerak di bidang contractor, fabrikasi, manufacturing, general trading, and labour supply. PT. Alfindo tidak memproduksi barang sendiri melainkan membutuhkan supplier dalam proses pengadaan barang. Namun, dalam proses pemilihannya PT. Alfindo masih mengalami kesulitan dalam memilih supplier yang terbaik, perusahaan juga belum memiliki kriteria khusus dalam melakukan penilaian terhadap supplier, serta membutuhkan waktu yang lama dalam proses pemilihannya. Penelitian ini bertujuan untuk menghasilkan suatu rancangan aplikasi yang dapat digunakan untuk pemilihan supplier, dan dapat membantu dalam memberikan evaluasi terhadap supplier berdasarkan kriteria yang dimiliki perusahaan, diantaranya harga, kualitas, pelayanan, waktu pengiriman, dan responsibilitas, serta dapat mengefisienkan waktu dalam pembuatan laporan. Penelitian dilakukan dengan metode observasi, wawancara, dan studi pustaka. Penelitian dilakukan di PT. Alfindo Banten Sukses Bersama. Sistem dirancang dengan menggunakan metode Analytical Hierarkhi Process (AHP) sebagai perhitungannya dan menggunakan Unified Modelling Language (UML) sebagai model perancangannya. Adapun software yang digunakan untuk membangun sistem ini adalah menggunakan Hypertext Preprocessor (PHP) dengan MySQL Server sebagai database-nya. Dari penilitian yang telah dilakukan maka dihasilkan sebuah sistem pendukung keputusan pemilihan supplier di PT. Alfindo dengan metode Analytical Hierarkhi Process (AHP), untuk membantu dalam proses pemilihan supplier terbaik sebagai pemasok barang-barang atau spare part alat kebutuhan industri yang dibutuhkan konsumen.
\end{abstract}

Kata kunci: Sistem Pendukung Keputusan, Pemilihan Supplier, AHP.

\section{LATAR BELAKANG}

Di era globalisasi seperti saat ini selain memunculkan perkembangan di bidang teknologi juga semakin banyak perusahaan dan bisnis baru yang bermunculan, contohnya seperti usaha di bidang kontraktor. Perusahaan-perusuhaan ini ada beberapa yang dikelola oleh usaha perorangan dan ada juga yang menjadi sub-kontrakator di perusahaan induknya. PT. Alfindo merupakan salah satu contoh perusahaan yang menginduk pada perusahaan lain. Hal ini menimbulkan persaingan yang semakin ketat antara pelaku-pelaku bisnis yang ada baik dalam industri barang maupun jasa.

Perusahaan yang dapat memadukan dengan baik antara strategi, teknologi, dan sumber daya yang ada, akan dapat bertahan dengan baik dalam persaingan dengan perusahaan yang bergerak di bidang industri yang sama. Banyak perusahaan kecil maupun besar yang ingin mengembangkan usahanya, tidak terkecuali pada perusahaan yang bergerak di bidang general contractor maupun pengadaan barang. Pada dasarnya setiap perusahaan mempunyai orientasi bisnis yang sama; yaitu menghasilkan profit atau keuntungan yang maksimal dengan meminimalkan biaya yang dikeluarkan. Hal tersebut dapat terwujud dengan pemilihan supplier atau pemasok yang tepat. Supplier atau pemasok merupakan mitra bisnis yang memegang peranan sangat penting dalam menjamin ketersediaan barang pasokan yang dibutuhkan oleh perusahaan.

Kinerja supplier atau pemasok akan mempengaruhi performansi atau kinerja perusahaan. Oleh karena itu, perusahaan perlu menilai supplier atau pemasok secara cermat dan tepat. Pemilihan pemasok merupakan kegiatan strategis, terutama apabila pemasok tersebut akan memasok item yang penting dan akan digunakan dalam jangka panjang.

PT. Alfindo merupakan perusahaan yang bergerak di bidang contractor, fabrikasi, manufacturing, engineering, general trading, and labour supply. Selain itu, PT. Alfindo juga memenuhi permintaan pengadaan barang kepada perusahaan-perusahaan besar untuk kebutuhan industri pabrik, seperti menyediakan alat-alat yang sering digunakan sebagai spare part untuk mesin industri. Dalam hal ini, PT.

Alfindo tidak memproduksinya sendiri melainkan harus mencari supplier atau pemasok lain yang memiliki stok barang yang sesuai dengan permintaan perusahaan. Terdapat kelemahan dalam pemilihan pemasok yang dilakukan oleh PT. Alfindo yaitu pengambil keputusan menilai hanya berdasarkan pada harga yang ditawarkan dan kualitas yang dimiliki barang secara subyektif.

Salah satu metode yang dapat digunakan untuk pemilihan supplier atau pemasok adalah dengan menggunakan metode Analitycal Hierarchy Process (AHP). AHP merupakan salah satu bentuk metode pengambilan keputusan yang pada dasarnya digunakan untuk menutupi kekurangan dari modelmodel sebelumnya. Perbedaan yang mencolok antara AHP dengan model pengambilan keputusan lainnya terletak dari jenis masukannya. Umumnya model pengambilan keputusan yang lain memakai input yang kuantitatif yang berasal dari data sekunder. Sehingga hanya dapat mengolah data-data yang 
bersifat kuantitaif. Sedangkan model AHP menggunakan persepsi manusia yang mengerti benar tentang permasalahan yang diajukan sebagai masukan utamanya.

\section{DASAR TEORI}

\section{A. Sistem Pendukung Keputusan}

Sistem pendukung keputusan atau Decission Support System (DSS) merupakan sistem informasi pada level manajemen dari suatu organisasi yang mengkombinasi kan data dan model analisis canggih atau peralatan data analisis untuk mendukung pengambilan keputusan yang semi terstruktur dan tidak terstruktur.

DSS dirancang untuk membantu pengambilan keputusan organisasional. DSS biasanya tersusun dari database, model grafis atau matematik yang digunakan untuk proses bisnis, dan antarmuka pengguna yang digunakan oleh pengguna agar dapat berkomunikasi dengan DSS (Al Fata, 2007 : 13).

\section{B. Supplier atau Pemasok}

Supplier atau pemasok merupakan salah satu rantai yang paling kritis atau penting bagi keuntungan dan kelangsungan hidup sebagian besar perusahaan.

Perusahaan kelas dunia tahu bahwa mutu produk dan layanan mereka sangat berhubungan langsung dengan mutu supplier atau pemasok dan produk serta layanan yang mereka berikan (Fernandez, dalam Rusdah dan Widyawati, $2013: 34$ )

\section{AHP (Analytical Hiearchy Process)}

Metode AHP (Analitycal Hierarchy Process) merupakan metode yang dikembangkan oleh Thomas L. Saaty sekitar tahun 1970, metode ini merupakan sebuah kerangka untuk pengambilan keputusan dengan efektif atas persoalan yang kompleks. Permasalahan pengambilan keputusan dapat menjadi kompleks karena adanya perlibatan beberapa tujuan maupun kriteria. Beberapa permasalahan yang dianggap kompleks seperti permasalah, perencanaan, penentuan alternatif, penyusunan prioritas, pemilihan kebijaksanaan, alokasi sumber, penentuan kebutuhan, peramalah kebutuhan, perencanaan performance, optimasi, dan pemecahan konflik (Saaty, dalam Wirdianto dan Unbersa, 2008). Suatu masalah dapat dikatakan kompleks jika struktur permasalahannya tersebut tidak jelas dan juga tidak tersedianya data dan informasi statistik yang akurat, sehingga input atau masukan yang digunakan dalam menyelesaikan masalah ini adalah intuisi atau persepsi manusia. Tetapi intuisi ini tidak datang dari sembarang orang, intuisi ini harus datang dari orangorang yang memahami dengan benar terhadap masalah apa yang ingin dipecahkannya (Wirdianto dan Unbersa, 2008 : 8).

Ada 4 prinsip dasar yang digunakan untuk memecahkan persoalan AHP ini, yaitu membuat hirarki, penilaian kriteria dan alternatif, menentukan prioritas, dan mengkur konsistensi (Kusrini, 2007). Secara spesifik, AHP cocok atau sesuai digunakan untuk mengatasi permasalahan pemilihan kandidat ataupun pengukuran prioritas yang memiliki beberapa sifat sebagai berikut :

a. Melibatkan kriteria-kriteria kualitatif yang sulit dikuantitatifkan secara eksak.

b. Masing-masing kriteria dapat memiliki sub-sub kriteria yang dapat dibentuk secara hirarki.

c. Penilaian dapat dilakukan oleh satu atau beberapa pengambil keputusan secara sekaligus.

d. Kandidat pilihan sudah tertentu dan terbatas jumlahnya.

Apabila suatu permasalahan pengambilan keputusan ingin diselesaikan dengan menggunakan metode AHP, permasalahan tersebut perlu dimodelkan dengan tiga hirarki umum, yakni tujuan, kriteria (termasuk subsub kriteria), dan alternatif. Konsep dasar dari AHP sebenarnya terletak dari penggunaan pairwise comparison matrix (matriks perbandingan berpasangan) untuk dapat mengahasilkan bobot relatif antar kriteria maupun alternatif.

Suatu kriteria akan dibandingkan dengan kriteria lainnya dalam hal seberapa penting terhadap pencapaian tujuaannya. Untuk menentukan matriks perbandingan berpasangan dapat menggunakan nilai atau skalaperbandingan yang biasa digunakan untuk mengukurnya yaitu dengan menggunakan skala 1 sampai 9 . Skala pengukuran ini biasa dikenal dengan skala perbandingan Saaty.

\section{Objek Penilitian}

PT. Alfindo Banten Sukses beralamat di jalan Letjend R Suprapto No. 25D Cilegon. Saat ini PT. Alfindo masih menggunakan sistem yang manual dalam melakukan proses pemilihan supplier yang akan diguanakan untuk memasok barang-barang permintaan konsumen yang menjadi konsumen dari PT. Alfindo dalam proyek pengadaan barang.

\section{ANALISIS DAN PERANCANGAN SISTEM}

\section{A. Metodologi:}

Metodologi penelitian yang digunakan penulis dalam melakukan penelitian ini adalah dengan menggunakan metode pengumpulan data agar mendapatkan data yang lengkap dan akurat. Metode pengumpulan data yang digunakan dalam penelitian ini adalah berupa observasi, wawancara, dan studi pustaka.Pengolah Administrator atau Ganti Passwordyang dapat digunakan admin untuk mengubah passwordnya.

\section{B. Sampling}

Berikut ini adalah perhitungan metode AHP untuk menentukan prioritas kriteria, dan dengan cara yang sama dapat digunakan untuk menentukan prioritas alternatif berdasarkan kriterianya masing-masing.

a. Membuat matriks perbandingan berpasangan

Pada tahap ini dilakukan penilaian perbandingan berpasangan antara satu kriteria dengan kriteria lainnya. 
Tabel 3.1 Matriks Perbandingan Berpasangan

\begin{tabular}{|l|c|c|c|c|c|}
\hline & Hargi & Kualitas & Pelinginan & $\begin{array}{l}\text { Waltus } \\
\text { Pengiriman }\end{array}$ & $\begin{array}{c}\text { Respon } \\
\text { Sibilitas }\end{array}$ \\
\hline Harga & 1 & 2 & 3 & 5 & 5 \\
\hline Kualitas & 0,50 & 1 & 3 & 3 & 1 \\
\hline Pelayanan & 0,33 & 0,33 & 1 & 2 & 3 \\
\hline $\begin{array}{l}\text { Waltu } \\
\text { Pengiriman }\end{array}$ & 0,20 & 0,33 & 0,50 & 1 & 2 \\
\hline Responsibilitas & 0,20 & 1 & 0,33 & 0,50 & 1 \\
\hline Jumlah & 2,23 & 4,66 & 7,83 & 11,5 & 12 \\
\hline
\end{tabular}

Angka 1 pada kolom harga baris harga menggambarkan tingkat kepentingan yang sama antara harga dengan harga, sedangkan angka 2 pada kolom kualitas baris harga menunjukan kualitas sedikit lebih penting dibandingkan harga. Angka 0,5 pada kolom harga baris kualitas merupakan hasil perhitungan 1 / nilai pada kolom kualitas baris harga (2). Angka yang lainnya diperoleh dengan cara yang sama.

b. Membuat matriks nilai kriteria

Matriks ini diperoleh dengan rumus berikut : Nilai baris kolom baru $=$ nilai baris kolom lama $/$ jumlah masing-masing kolom lama.

Tabel 3.2 Matriks Nilai Kriteria

\begin{tabular}{|c|c|c|c|c|c|c|c|}
\hline & Hanga & Kualitas & $\begin{array}{c}\text { Pelavans } \\
n\end{array}$ & $\begin{array}{l}\text { Waktu } \\
\text { Pengiriman }\end{array}$ & $\begin{array}{l}\text { Respos } \\
\text { sibilitas }\end{array}$ & Jumlah & $\begin{array}{l}\begin{array}{l}\text { Phiori } \\
\text { tas }\end{array} \\
\text { tal }\end{array}$ \\
\hline Harga & 0,45 & 0,43 & 0,38 & 0,43 & 0,42 & 2,11 & 0,42 \\
\hline Kulitas & 0,22 & 0.21 & 0,38 & 0,26 & 0,08 & 1,15 & 0,23 \\
\hline Pedayanan & 0,14 & 0,07 & 0,13 & 0,17 & 0,25 & 0.76 & 0,15 \\
\hline $\begin{array}{l}\text { Waktu } \\
\text { Penginiman }\end{array}$ & 0,09 & 0,07 & 0,06 & 0,09 & 0,17 & 0,48 & 0,10 \\
\hline $\begin{array}{l}\text { Respon } \\
\text { Schilitas }\end{array}$ & 0,09 & 0,21 & 0,04 & 0,04 & 0,08 & 0,46 & 0,09 \\
\hline
\end{tabular}

Nilai 0,45 pada kolom harga baris harga diperoleh dari nilai kolom harga baris harga tabel 3.1 dibagi jumlah kolom harga tabel 3.13. Nilai kolom jumlah pada tabel 3.2 diperoleh dari penjumlahan pada tiap barisnya. Nilai pada kolom prioritas diperoleh dari nilai pada kolom jumlah dibagi dengan jumlah kriteria, dalam hal ini 5 (lima).

c. Menghitung Principle Eigen Value (max)

Tabel 3.3 Hasil Max Matrik Kriteria

\begin{tabular}{|l|c|c|c|}
\hline & $\begin{array}{c}\text { Jumlah Matriks } \\
\text { Perbandingan } \\
\text { Berpasangan }\end{array}$ & Proritas & Hasil \\
\hline Harga & 2,23 & 0,42 & 0,94 \\
\hline Kualitas & 4,66 & 0,23 & 1,07 \\
\hline Pelayanan & 7,83 & 0,15 & 1,17 \\
\hline $\begin{array}{l}\text { Waktu } \\
\text { Pengiriman }\end{array}$ & 11,5 & 0,10 & 1,15 \\
\hline Responsibilitas & 12 & 0,09 & 1,08 \\
\hline \multicolumn{3}{|c|}{ Jumlah } & 5,41 \\
\hline
\end{tabular}

d. Menghitung nilai Consistency Index dan Consistency Ratio

1) Consistency Index Jumlah $\max =5,41$

$$
\mathrm{N}=5
$$

$\mathrm{CI}=0,10$

2) Consistency Ratio

$\mathrm{CI}=0,10$

$\mathrm{IRC}=1,12$
CR

$$
=0,09 \%
$$

Keterangan : Nilai IRC didapat dari daftar indeks random konsistensi tabel 3.3. Hasil CR harus lebih kecil dari 0,1 atau $<10 \%$. Karena nilai $\mathrm{CR}<0,1$, maka rasio konsistensi dari perhitungan tersebut diterima.

\section{HASIL DAN PEMBAHASAN}

Sistem ini dibuat dengan bahasa pemrograman PHP, berikut adalah beberapa tampilan dari program pemilihan supplier :

a.

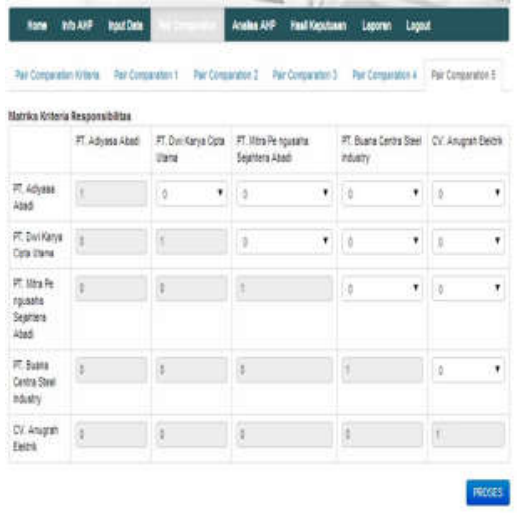

Gambar 4.1 Perbandingan Berpasangan Matriks Kriteria

b.

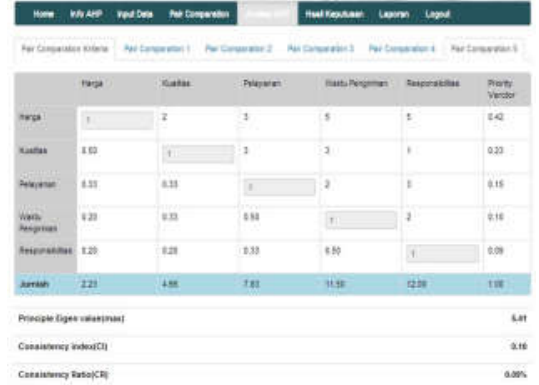

Gambar 4.2 Analisa hasil perhitungan AHP

c.

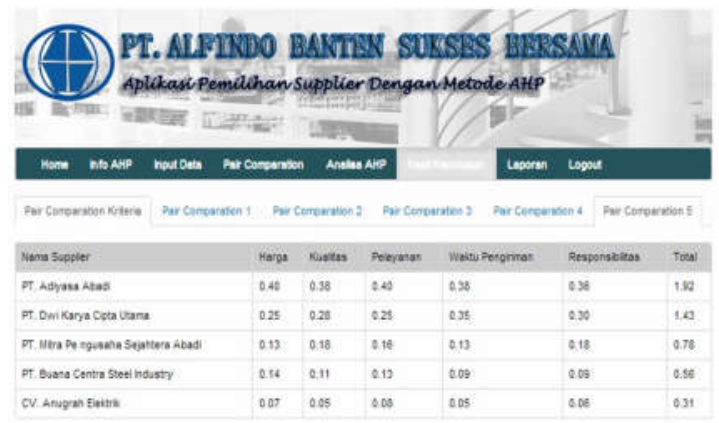

Gambar 4.3 Hasil supplier terpilih 


\section{KESIMPULAN}

a. Dalam merancang sebuah aplikasi untuk pemilihan supplier ini menggunakan model UML (Unified Modelling Language) dengan empat model perancangan yaitu use case diagram, activity diagram, class diagram, dan sequence diagram, yang masing-masing diagramnya terdiri dari datadata berikut : login, input data, pairwise comparation, analisa AHP, hasil perhitungan AHP, cetak laporan, logout.

b. Selain dirancang dengan model UML, sistem ini pun dibangun dengan bahasa pemrograman PHP (Hypertext Preprocessor) serta menggunakan MySQL sebagai databasenya dan juga dengan menerapakan AHP (Analytical Hierarchy Process) sebagai metode perhitungannya untuk membantu pengambilan keputusan dalam memilih supplier terbaik..

\section{DAFTAR PUSTAKA}

1. Taufiq, R. (2013). "Rancang Bangun Sistem Pendukung Keputusan Penilaian Kinerja Kependidikan Menggunakan Metode Analytical Hierarchi Process (Studi Kasus Di Fakultas Teknik Universitas Muhammadiyah Tangerang)." Jurnal Tekno Insentif Kopwil4. Vol. 7. No. (2). $36-44$.

2. Artika, R. (2013). "Penerapan Analitycal Hierarchy Procces (AHP) Dalam Pendukung Keputusan Penilaian Kinerja Guru Pada SD Negeri 095224." Pelita Informatika Budi Darma. Vol. IV. No. (3). 1 - 6.

3. Kusrini Dan Gole, A W. (2007). "Sistem Pendukung Keputusan Penentuan Prestasi Pegawai Nakertrans Sumba Barat Di Waikabubak." SNATI 2007. ISSN: 1907-5022. Hal. D-47 s/d D-52.

4. Tominanto. (2012). "Sistem Pendukung Keputusan Dengan Metode Analytical Hierarchy Process (AHP) Untuk Penentuan Prestasi Kinerja Dokter Pada Rsud. Sukoharjo." INFOKES. Vol. 2. No. (1). 1 - 15. [7] Indah, (2009), Sistem Informasi Geografis Fasilitas Kota Bogor Menggunakan Framework Pmapper, Institut Pertanian Bogor, Bogor pada tanggal 23 Juni 2014 pukul 13.14 WIB, diakses di http://repository.ipb.ac.id/bitstream/handle/123456789/1 $3023 /$ G09ika.pdf?sequence $=10$

[8] Murdiyanto, (2010), Simulasi Daerah Banjir Menggunakan Sistem Informasi Geografis Di Kabupaten Sragen, Universitas Islam Negeri Malang, Malang. , pada tanggal 25 Juni 2014 pukul 13.14 WIB, diakses di http://lib.uin- 